\title{
Safety and neutralizing rabies antibody in healthy subjects given a single dose of rabies immune globulin caprylate/chromatography purified
}

This article was published in the following Dove Press journal:

Clinical Pharmacology:Advances and Applications

\author{
Kim Hanna \\ Maria Cristina Cruz \\ Elsa Mondou \\ Edward Corsi \\ Peter Vandeberg
}

Grifols Bioscience Research Group, Grifols Inc, Research Triangle Park, NC, USA
Correspondence: Elsa Mondou Grifols Bioscience Research Group, Grifols Inc, 420I Research Commons, 79 TW Alexander Drive, Research Triangle Park, NC 27709, USA

$\mathrm{Tel}+\mathrm{l} 9196985399$

Email elsa.mondou@grifols.com
Background: Rabies immune globulin (RIG) and vaccination series are necessary for postexposure prophylaxis. A new formulation of RIG (human) purified by caprylate/chromatography (RIG-C) was evaluated.

Trial registration: ClinicalTrials.gov identifier: NCT02139657.

Materials and methods: This open-label, single-arm study in healthy subjects evaluated neutralizing rabies antibody concentrations produced from a single $20 \mathrm{IU} / \mathrm{kg}$ intramuscular (IM) dose of RIG-C as measured by rapid fluorescent focus inhibition test ( $50 \%$ neutralization endpoint) 1-hour postdose and on days 1, 2, 4, 6, 8, 10, 14, 18, and 21.

Results: Twelve subjects were enrolled into the study. No discontinuations, serious adverse events (AEs), or treatment-emergent clinically significant changes in laboratory parameters were observed. All AEs resolved and were mild except 1 moderate AE of oropharyngeal pain. Injection site pain (4 subjects) was most commonly reported. RIG-C produced a rapid increase in neutralizing rabies antibody: mean value $0.113 \mathrm{IU} / \mathrm{mL}$ at 24 hours after IM injection, peak on day $4(0.132 \mathrm{IU} / \mathrm{mL})$, persisting through day $21(0.116 \mathrm{IU} / \mathrm{mL})$. The mean reciprocal titer was 11.5 by day 2 ; the peak value of 12.1 was achieved on day 4 ; and a mean value $\geq 10.6$ was maintained through day 21 .

Conclusion: RIG-C was well tolerated and provided neutralizing rabies antibodies, which combined with vaccine series after rabies exposure, should result in effective prophylaxis per World Health Organization/Centers for Disease Control and Prevention guidelines.

Keywords: rabies, rabies immune globulin, RIG-C, prophylaxis, rabies neutralizing antibody titers, GTI1301

\section{Plain language summary}

People who have been exposed to potentially rabid animals (ie, bats, foxes, raccoons) need antirabies virus antibodies and rabies vaccination to prevent death from rabies infection. This clinical study tested a new formulation of anti-rabies virus antibodies that delivers twice the amount of antibodies per volume as compared to other products currently in the market. Reducing the volume in half offers potentially fewer injections, and doubling the strength allows more antibodies per milliliter to be injected directly into the wound site. To determine whether this medication was safe and well tolerated, 12 healthy volunteers were injected with this new medication and were observed for 21 days. No one withdrew from the study and had serious reactions and any severe reactions from the medication. All reactions were mild, except for a single subject with throat pain, and all reactions disappeared on their own. Most frequently reported was pain at the injection site. This medication was well tolerated and provided enough anti-rabies antibodies, which combined with rabies vaccination, should give effective protection against rabies. The US Food and Drug Administration approved this new formation with the name HyperRAB ${ }^{\circledR}$ (rabies immune globulin [human]) $300 \mathrm{IU} / \mathrm{mL}$. 


\section{Introduction}

Rabies is usually transmitted to humans via the bites of infected animals, resulting in fatal encephalitis. Once human rabies manifests, there is no treatment that mitigates mortality. Thus, the only effective intervention is prevention. Rabies has been known as a scourge through five millennia since the earliest reference to rabies in Mesopotamia around 2300 BCE. ${ }^{1}$ From the time of Fracastoro's treatise in 1546, rabies has been referred to as the incurable wound, and Louis Pasteur was the first to break the inexorable chain of transmission. Pasteur successfully immunized 9-year-old Joseph Meister with 13 inoculations of desiccated, infected rabbit spinal cord material after he received a severe bite injury from a rabid dog. ${ }^{2}$ Since that time, researchers have diligently sought improvements in postexposure prophylaxis (PEP), yet rabies still causes human mortality at an estimated rate of 26,400 to 61,000 deaths per year worldwide. ${ }^{3}$

Following a bite or nonbite exposure to an animal suspected of rabies infection, PEP requires both passive (rabies immune globulin [RIG]) and active (vaccine) immunization in persons who have not been immunized prior to exposure. ${ }^{3,4}$ Human RIG (hRIG) should not be given in the same syringe or at the same anatomical site as the initial dose of rabies vaccine. ${ }^{4}$ If anatomically possible, up to the full dose of hRIG (20 IU/ $/ \mathrm{kg}$ body weight) must be injected into and around the wound site, enabling the anti-rabies antibodies to infiltrate the tissue surrounding the wound. Any remaining hRIG should be injected intramuscularly (IM) into the deltoid muscle or into the lateral thigh muscle. It is preferable to inject hRIG far from the site of rabies vaccine administration to prevent neutralization of the vaccine. hRIG is generally administered at the same time as the first rabies vaccine dose. If hRIG was not given when vaccination began, it may be administered at any time up to 7 days after the first vaccine dose.

The importance of RIG is multifaceted. Rabies virus neutralization at the wound entry site critically inhibits virus propagation and viral spread via fast axonal transport to the brain. In addition, passive immunization with RIG provides an immunologic bridge until active vaccine-induced immunization produces adequate virus neutralizing antibodies ( $\geq 0.5 \mathrm{IU} / \mathrm{mL}$ ) approximately $7-10$ days after the first vaccine dose. ${ }^{5} \mathrm{hRIG}$ is generally preferred over equine RIG due to the possibility of equine RIG-associated serum sickness (in less than $1 \%-3 \%$ of recipients) and the higher dosage requirement for equine RIG, which has a shorter half-life in humans. ${ }^{3}$ However in certain geographic locations, equine RIG is utilized in humans because of cost and availability constraints for hRIG. ${ }^{6,7}$ Rabies PEP failures are rare among the estimated 20 million people who receive PEP each year. ${ }^{3}$
When rabies PEP fails, it is generally attributed to deviations in standard protocol (eg, late PEP initiation, failure to infiltrate all wounds with RIG, incomplete vaccination series).

$\mathrm{hRIG}$ is prepared from pooled plasma of donors who are hyperimmunized with rabies vaccine. Current commercially available hRIG preparations, including Grifols' HyperRAB ${ }^{\circledR}$ S/D, ${ }^{8}$ Sanofi Pasteur's Imogam ${ }^{\circledR}$ Rabies - HT, ${ }^{9}$ and Kedrion Biopharma/Kamada's KEDRAB ${ }^{\mathrm{TM}}$ (also known as Kam$\left.\mathrm{RAB}^{\mathrm{TM}}\right){ }^{10}$ have a potency of $150 \mathrm{IU} / \mathrm{mL}$.

The new US Food and Drug Administration-approved Grifols product HyperRAB ${ }^{\circledR} 300 \mathrm{IU} / \mathrm{mL}$ [RIG (human)] solution for infiltration and IM injection caprylate/chromatography purified (RIG-C) ${ }^{11}$ has twice the potency of currently available hRIG options combined with a low buffer capacity. With its new $300 \mathrm{IU} / \mathrm{mL}$ formulation, RIG-C allows for administration of smaller volumes that reach physiologic $\mathrm{pH}$ quickly when exposed to body fluids. In addition, RIG-C benefits from state-of-the-art manufacturing techniques similar to those used for commercially available Gamunex ${ }^{\circledR}-C^{12}$

Caprylate/chromatography techniques enhance purity and yield. Because the injection volume of RIG-C is half that of the currently marketed $150 \mathrm{IU} / \mathrm{mL}$ hRIG preparations, it may be easier to administer the complete RIG-C dose by infiltrating more RIG-C around the bite wound and injecting less volume IM. Indeed, recently proposed changes to the World Health Organization (WHO) Policy on Rabies Vaccines and Rabies Immunoglobulins recommend local infiltration of as much RIG as possible into and around the wound, as this is the most effective approach in preventing rabies. ${ }^{13}$ For example, a $70 \mathrm{~kg}$ adult given $300 \mathrm{IU} / \mathrm{mL}$ RIG-C at $20 \mathrm{IU} /$ $\mathrm{kg}$ dose would require $4.7 \mathrm{~mL}$ infiltrated around the wound with any remaining volume injected IM, instead of having to inject twice the volume $(9.3 \mathrm{~mL})$ of a $150 \mathrm{IU} / \mathrm{mL}$ hRIG product. Considering the typical maximum IM injection volume is $5 \mathrm{~mL}$ for a single injection site, ${ }^{14}$ the higher RIG-C concentration would minimize the number of IM injections.

The objectives of this study were to characterize the neutralizing rabies antibody levels and to evaluate the safety of a single IM injection in healthy human volunteers. It is important to study passive immunity by RIG-C, as vaccineinduced host immunity is not fully developed during this initial period and local inhibition of axonal viral transport in the first $7-10$ days after rabid animal bite is critical for survival. ${ }^{15,16}$

\section{Materials and methods}

This was a single-arm, open-label study conducted at Celerion (Tempe, AZ, USA), a company that conducts studies in healthy volunteers. The study was first registered on May 
15, 2014. ClinicalTrials.gov identifier is NCT02139657. The study was designed to assess anti-rabies virus antibody titers as measured by rapid fluorescent focus inhibition test (RFFIT) and to evaluate the safety of a single IM injection of 20 IU/kg RIG-C in 12 healthy subjects (18-65 years old) for up to 21 days after administration. Subjects were required to have no confounding medical conditions, to have adequate renal and hepatic function, to be naïve to rabies vaccine and RIG, and not to be on antiviral treatment at screening. Subjects were excluded if they received corticosteroids, immunosuppressants, or immunomodulators within 6 weeks before screening, or if laboratory results indicated acute or chronic infection with hepatitis A, B, C, human immunodeficiency virus, or parvovirus B19.

During the screening period of up to 21 days, safety assessments and laboratory tests were performed to ascertain eligibility (Figure 1). Subjects were confined at the clinic overnight prior to the "baseline/treatment, study day 0" visit. A single IM dose of RIG-C was administered on day 0 , followed by repeated measurements of rabies virus antibody concentrations on days $1,2,4,6,8,10,14,18$, and 21. Oral or topical nonsteroidal anti-inflammatory drugs, acetaminophen, antihypertensive drugs, or antihistamines were not allowed 24 hours before and after RIG-C administration but were otherwise permitted during the study.

\section{Ethics approval and consent to participate}

Standards for Good Clinical Practices were adhered to for all procedures in this study. The investigators ensured that the study was conducted in full conformance with appropriate local laws and regulations and the Declaration of Helsinki. The protocol for this study was prepared in accordance with
International Conference on Harmonisation Guidelines. The study protocol and site received institutional review board (IRB) approval from Chesapeake IRB. All subjects provided written informed consent for the complete study at the screening visit before any study-specific procedure took place, and the privacy rights of all subjects were observed.

\section{RIG-C}

Grifols Therapeutics developed a manufacturing process that employs caprylate precipitation and depth filtration, caprylate incubation, and chromatographic steps in the immunoglobulin $\mathrm{G}$ purification scheme. This is the same process currently used to manufacture Gamunex-C with the final product being more concentrated to a $16.5 \%$ protein concentration. The primary differences between RIG-C and Gamunex-C are as follows: 1) RIG-C has antibody specificity against rabies derived from plasma of healthy volunteers vaccinated with rabies vaccine and 2) RIG-C has a higher immune globulin concentration (16.5\%) than Gamunex-C (10\%).

RIG-C is a sterile solution of anti-RIG stored in glass vials at $2^{\circ} \mathrm{C}-8^{\circ} \mathrm{C}\left(36^{\circ} \mathrm{F}-46^{\circ} \mathrm{F}\right)$. Each vial of RIG-C contains a $16.5 \%$ protein solution of human immune globulin with a minimum of $300 \mathrm{IU} / \mathrm{mL}$ of rabies antibody as determined by RFFIT. RIG-C was supplied to the study site in $5 \mathrm{~mL}$ vials (1500 IU/vial) from a single lot.

Subjects received a single $20 \mathrm{IU} / \mathrm{kg}$ dose of RIG-C via IM injection into the lateral thigh muscle. This is the standard dosage based on recommendations by the Centers for Disease Control and Prevention and Advisory Committee on Immunization Practices (ACIP). ${ }^{5}$ The volume of RIG-C injected at a single injection site did not exceed $5 \mathrm{~mL}$. If the required volume was in excess of $5 \mathrm{~mL}$, multiple injection sites (ie, both legs) were used.

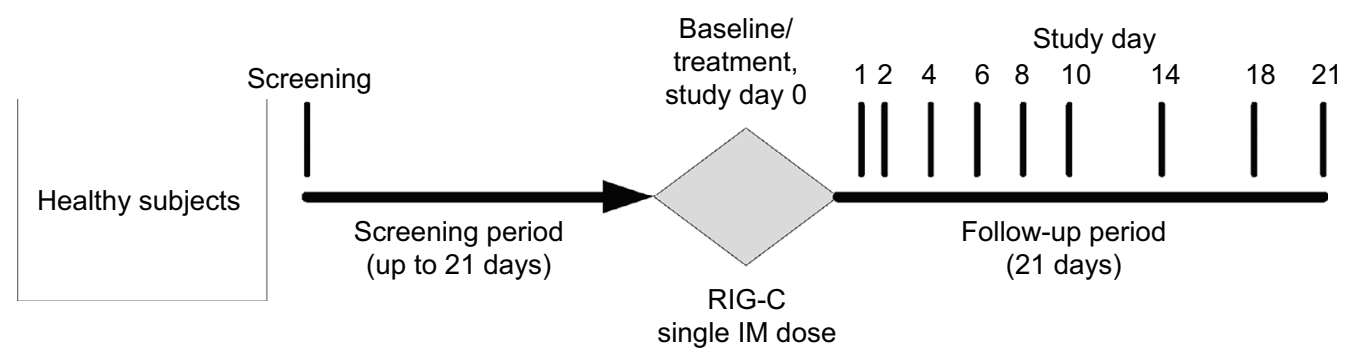

$(20 \mathrm{IU} / \mathrm{kg})$

Figure I Study design.

Notes: Written informed consent was obtained from all prospective healthy subjects at the screening visit prior to performing any study procedures. At the screening visit, subjects were screened by physical examination and laboratory assessments. Eligibility for the study was determined by the protocol inclusion and exclusion criteria over a screening period of up to $2 I$ days. Subjects who met all eligibility criteria received a single dose of RIG-C ( $20 \mathrm{IU} / \mathrm{kg})$ at the baseline/treatment, study day 0 visit. Subjects then entered a postadministration follow-up period of 21 days, with clinic visits on study days I, 2, 4, 6, 8, 10, 14, 18 , and 21 . The total duration of study participation for subjects who completed the study was up to 43 days.

Abbreviations: IM, intramuscular; RIG-C, rabies immune globulin purified by caprylate/chromatography. 


\section{RFFIT}

The primary outcome measure was the anti-rabies virus antibody titers and concentrations (IU/mL) measured by RFFIT. RFFIT is regarded as the standard rabies virus neutralization assay and the benchmark method for measuring rabies-specific antibodies. ${ }^{4,17}$ It is also the method used to assign potency to the RIG-C product. Serum samples were obtained during the screening visit, at baseline study day 0 (immediately prior to RIG-C administration), at 1 hour ( \pm 10 minutes) postadministration, and on study days 1 (approximately 24 hours), 2, 4, 6, 8, 10, 14, 18, and 21 postadministration. The samples were stored at $-70^{\circ} \mathrm{C}$ and analyzed at Kansas State Veterinary Diagnostic Laboratory at Kansas State University College of Veterinary Medicine (Manhattan, KS, USA). All samples were assayed in a single batch to avoid test-to-test variability. RFFIT was performed according to standard validated procedures: ${ }^{18-25} 1$ ) mixing the challenge virus standard 11 (CVS-11) strain of rabies virus with test samples containing neutralizing antibodies and 2) inoculating the reaction mixture into a baby hamster kidney (BHK) cell culture system. After a 20- to 24-hour incubation period, the inoculated BHK cells were examined microscopically for percentage of infectivity. The absence of infectivity constituted a positive neutralization reaction and indicated the presence of virus-specific antibodies in the sample.

The RFFIT neutralization endpoint titer was defined as the highest sample dilution at which $50 \%$ of the observed microscopic fields contained at least 1 infected cell. The rabies virus neutralizing antibodies titers ( $50 \%$ neutralization, ED50) were mathematically interpolated using the Reed and Muench formula, and the reciprocal of the $50 \%$ endpoint titer was determined ( 10 to the $\log$ power of the $50 \%$ endpoint dilution) ${ }^{26}$ The endpoint neutralization titer of the test serum was converted into $\mathrm{IU} / \mathrm{mL}$ values by calibrating from the endpoint neutralization titer of the US Standard Rabies Immune Globulin, Lot R-3, 59 IU (1st WHO International Standard), which was measured in the same assay with an assigned value of $2.0 \mathrm{IU} / \mathrm{mL}$.

The data are reported in both $\mathrm{IU} / \mathrm{mL}$ and in titer values. Although IU $/ \mathrm{mL}$ has become a universal reporting standard, it is important to report titer values as well to provide context for historical comparison with prior product. The lower limit of quantification (LLOQ) was determined to be $0.1 \mathrm{IU} /$ $\mathrm{mL}$ during validation. However for this study, the limit of detection (LOD) was determined to be $0.05 \mathrm{IU} / \mathrm{mL}$ using the 95th percentile method on the baseline (predose) samples. Therefore, the results were reported to a minimum $0.05 \mathrm{IU} /$ $\mathrm{mL}$, and the LOD was determined to be 5 when measured in reciprocal titer. For the purpose of analyzing results, values below the LOD were reported as $0.05 \mathrm{IU} / \mathrm{mL}$ or a titer of 5 .

\section{Safety}

Safety was evaluated based on treatment-emergent adverse events (AEs) at all time points; clinical laboratory parameters (chemistry, hematology, urinalysis) at screening, baseline, and day 21; and vital signs at screening, baseline, between 1 and 3 hours after RIG-C injection, and on days 1, 2, 4, 6 , $8,10,14,18$, and 21 .

\section{Statistical analyses}

Rabies virus neutralizing antibody titer and rabies virus neutralizing antibody concentrations (reported in IU/mL) at each visit were summarized. The data for antibody titers were reported as reciprocals. Descriptive statistics and frequency counts were provided for categorical variables. All descriptive statistics were calculated in $\mathrm{SAS}^{\circledR}$ Version 9.3 or higher. No inferential statistics were performed. A sample size of 12 subjects (to assure 10 completers) was chosen based on previous experience with similar studies and was not based on formal sample size calculations.

\section{Results}

Thirty-two subjects were screened at the Celerion study center. Twelve subjects met eligibility criteria in terms of good health and acceptable laboratory results. There were 20 screen failures for reasons that included abnormal laboratory values $(n=9)$, subject decision not to participate $(n=4)$, and poor veins/vascular problems $(n=3)$. All 12 healthy subjects enrolled and completed the study between March 21, 2014, and May 29, 2014. All 12 subjects were included in the safety population and were evaluated for measurement of rabies antibody levels.

Demographic characteristics are summarized in Table 1. The 12 enrolled subjects were primarily Caucasian $(n=9)$ and women ( $\mathrm{n}=9$ ) with a median age of 40 years (range 25-53), median weight of $82.6 \mathrm{~kg}$ (range 58.7-109.7), and median body mass index of $32.1 \mathrm{~kg} / \mathrm{m}^{2}$. Three African Americans participated (two men, one woman). All subjects received the full IM dose of $20 \mathrm{IU} / \mathrm{kg}$ RIG-C. The total volume administered ranged from $4 \mathrm{~mL}$ to $7.3 \mathrm{~mL}$ (mean $5.68 \mathrm{~mL}$; median $5.55 \mathrm{~mL}$ ).

\section{RFFIT}

The activity level of rabies virus neutralizing antibody following the single IM dose of RIG-C on day 0 is depicted in Table 2 and Figure 2. At screening and day 0 predose time points, 
Table I Subject demographics

\begin{tabular}{lll}
\hline Characteristic & Attribute & Overall $(\mathbf{n}=\mathbf{I} 2)$ \\
\hline Sex & Female & $9(75 \%)$ \\
& Male & $3(25 \%)$ \\
Race & Black or African American & $3(25 \%)$ \\
& White & $9(75 \%)$ \\
Ethnicity & Hispanic or Latino & $7(58 \%)$ \\
& Not Hispanic or Latino & $5(42 \%)$ \\
Age (years) & Mean (SD) & $41.0(9.7)$ \\
& Median (range) & $40.0(25-53)$ \\
Weight (kg) & Mean (SD) & $84.8(14.9)$ \\
& Median (range) & $82.6(58.7-109.7)$ \\
Height (cm) & Mean (SD) & $167.3(10.7)$ \\
& Median (range) & $167.0(152-185)$ \\
Body mass index & Mean (SD) & $30.4(4.9)$ \\
$\left(\mathrm{kg} / \mathrm{m}^{2}\right)$ & Median (range) & $32.1(20.9-37.9)$ \\
\hline
\end{tabular}

Abbreviation: SD, standard deviation.

Table 2 Summary of rabies virus antibody levels $(\mathrm{IU} / \mathrm{mL})$ following a single $20 \mathrm{IU} / \mathrm{kg}$ dose of RIG-C $(n=12)$

\begin{tabular}{llll}
\hline Time point & Mean (SD) & Median (range) & $\begin{array}{l}\text { Geometric } \\
\text { mean (SD) }\end{array}$ \\
\hline Screening & $<0.05$ & $<0.05$ & $<0.05$ \\
Day 0 predose & $<0.05$ & $<0.05(<0.05-0.07)$ & $<0.05$ \\
Day 0 hour I & $<0.05$ & $<0.05(<0.05-0.10)$ & $<0.05$ \\
Day I & $0.113(0.038)$ & $0.11(<0.05-0.21)$ & $0.106(0.040)$ \\
Day 2 & $0.126(0.028)$ & $0.12(0.09-0.21)$ & $0.124(0.024)$ \\
Day 4 & $0.132(0.022)$ & $0.12(0.11-0.19)$ & $0.130(0.020)$ \\
Day 6 & $0.126(0.016)$ & $0.12(0.11-0.17)$ & $0.126(0.015)$ \\
Day 8 & $0.128(0.024)$ & $0.12(0.11-0.18)$ & $0.126(0.021)$ \\
Day 10 & $0.118(0.007)$ & $0.12(0.11-0.13)$ & $0.118(0.007)$ \\
Day 14 & $0.118(0.006)$ & $0.12(0.10-0.12)$ & $0.117(0.007)$ \\
Day 18 & $0.118(0.006)$ & $0.12(0.11-0.13)$ & $0.118(0.006)$ \\
Day 2I & $0.116(0.007)$ & $0.12(0.10-0.12)$ & $0.116(0.007)$ \\
\hline Ab
\end{tabular}

Abbreviations: RIG-C, rabies immune globulin purified by caprylate/ chromatography; SD, standard deviation. anti-rabies virus antibody concentrations were all below the LLOQ (range $<0.05-0.07 \mathrm{IU} / \mathrm{mL}$ ). Of the 12 subjects, 2 had levels of $<0.05 \mathrm{IU} / \mathrm{mL}$ at screening and of $0.07 \mathrm{IU} / \mathrm{mL}$ at day 0 . It should be noted that the LLOQ was determined to be $0.1 \mathrm{IU} / \mathrm{mL}$ during validation, and assay sensitivity below 0.1 $\mathrm{IU} / \mathrm{mL}$ has some margin of variability. Subsequent to RIG-C administration, rabies virus neutralizing antibody activity increased from $\leq 0.07 \mathrm{IU} / \mathrm{mL}$ to a median of $0.11 \mathrm{IU} / \mathrm{mL}$ on day 1 (24 hours after RIG-C administration), and the median value remained $0.12 \mathrm{IU} / \mathrm{mL}$ from days 2 through 21 . Mean anti-rabies virus antibody levels were highest on day 2 through $8(0.126 \mathrm{IU} / \mathrm{mL}$ through $0.132 \mathrm{IU} / \mathrm{mL})$; was $0.118 \mathrm{IU} / \mathrm{mL}$ at days 10,14 , and 18 ; and decreased slightly to $0.116 \mathrm{IU} / \mathrm{mL}$ on day 21. Geometric mean values followed a similar pattern. It is important to note that, by day 4 , antibody levels in all subjects rose higher than $0.10 \mathrm{IU} / \mathrm{mL}$. The 2 subjects with $0.07 \mathrm{IU} / \mathrm{mL}$ at day 0 predose (baseline) experienced marked increases to peak values of $0.19 \mathrm{IU} / \mathrm{mL}$ and $0.21 \mathrm{IU} / \mathrm{mL}$ (respectively), which were the highest levels among all subjects analyzed.

Table 3 and Figure 3 illustrate the prompt increase in reciprocal rabies virus antibody titer following RIG-C administration ( $\mathrm{n}=12$ subjects). Reciprocal titer results mirrored the data presented in $\mathrm{IU} / \mathrm{mL}$ and are expressed herein using both modalities for ease of comparison with prior historical results. Briefly, the reciprocal of the anti-rabies virus antibody titer was $<5$ for all subjects at screening and for 10 subjects at day 0 (predose). Mean anti-rabies virus reciprocal antibody titers increased rapidly in 24 hours (10.3) with peak mean titers occurring at day 4 (12.1). On day 2, the reciprocal titer was 11 in 7 subjects, and 10,12, and 19 in 1 subject each. The

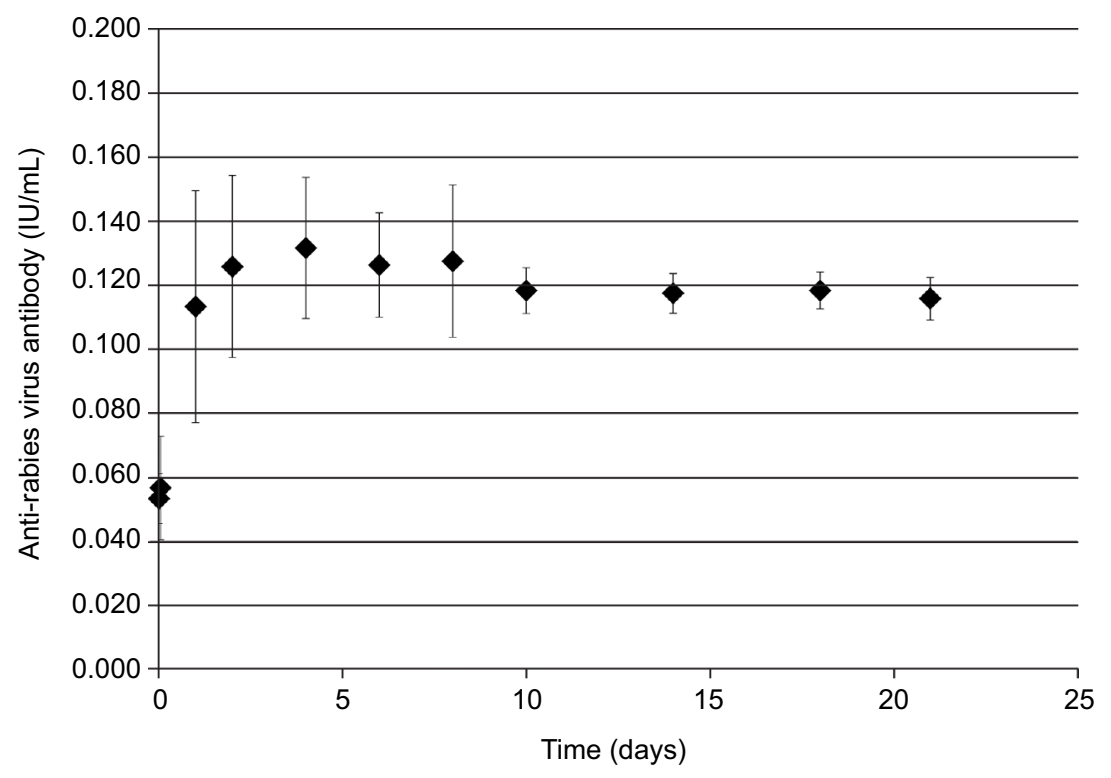

Figure 2 Anti-rabies virus antibody concentrations by RFFIT (IU/mL) following a single IM dose of RIG-C (mean \pm SD).

Abbreviations: RFFIT, rapid fluorescent focus inhibition test; IM, intramuscular; RIG-C, rabies immune globulin purified by caprylate/chromatography; SD, standard deviation. 
lowest value of 8 occurred in 1 subject, who had a reciprocal titer of 11 on day 1 and 12 on day 4. Thus, 11 of the 12 subjects had a reciprocal titer of $\geq 10$ on day 2 , and all subjects had a reciprocal titer of $\geq 10$ by day 4 . Mean antibody titers decreased slightly after the peak on day 4 but remained $\geq 10.6$ through day 21 . A reciprocal titer $\geq 9$ was recorded from day 14 through 21 in all subjects.

\section{Safety}

The single dose of RIG-C (20 IU/kg) via IM injection was well tolerated. Table 4 provides a summary of the AEs. Six subjects had no AEs, and 6 subjects (50\%) had 15 AEs. All

Table 3 Summary of reciprocal of rabies virus antibody titers by visit following a single $20 \mathrm{IU} / \mathrm{kg}$ dose of RIG-C $(n=12)$

\begin{tabular}{llll}
\hline Time point & Mean (SD) & Median (range) & $\begin{array}{l}\text { Geometric } \\
\text { mean (SD) }\end{array}$ \\
\hline Screening & $<5$ & $<5$ & $<5$ \\
Day 0 predose & $<5$ & $<5(<5-6)$ & $<5$ \\
Day 0 hour I & $<5$ & $<5(<5-9)$ & $<5$ \\
Day I & $10.3(3.39)$ & $10.0(<5-19)$ & $9.7(3.4 I)$ \\
Day 2 & $11.5(2.58)$ & $11.0(8-19)$ & $11.3(2.2)$ \\
Day 4 & $12.1(1.98)$ & $11.0(10-17)$ & $12.0(1.79)$ \\
Day 6 & $11.5(1.37)$ & $11.0(10-15)$ & $11.5(1.32)$ \\
Day 8 & $11.6(2.02)$ & $11.0(10-16)$ & $11.4(1.83)$ \\
Day 10 & $10.8(0.72)$ & $11.0(10-12)$ & $10.8(0.7 I)$ \\
Day 14 & $10.8(0.62)$ & $11.0(9-11)$ & $10.7(0.66)$ \\
Day 18 & $10.8(0.58)$ & $11.0(10-12)$ & $10.8(0.58)$ \\
Day 2I & $10.6(0.67)$ & $11.0(9-11)$ & $10.6(0.7)$ \\
\hline
\end{tabular}

Abbreviations: RIG-C, rabies immune globulin purified by caprylate/ chromatography; SD, standard deviation.
AEs were mild, except for a single subject with moderate oropharyngeal pain. All AEs resolved without sequelae. All AEs were considered potentially related by the investigator, except for two AEs (procedural dizziness and pain in the extremity) that were unrelated. Four subjects had 10 AEs within 24 hours of RIG-C administration (all related). There were no new AEs between 24 and 72 hours postdose. The AEs occurring $>72$ hours after IM injection were product-related injection site pain, nasal congestion, and oropharyngeal pain, as well as unrelated procedural dizziness and limb pain in one subject each. There were no deaths, no serious AEs, and no discontinuations due to AEs. Clinical laboratory (chemistry, hematology, and urinalysis) and vital signs data showed no pattern of abnormality posttreatment.

\section{Discussion}

Once encephalitis symptoms appear, rabies is an incurable infectious disease with only 10 known human survivors worldwide. ${ }^{1}$ When rabies manifests clinically, there is no treatment that can halt its inexorable progression to death. In the absence of early and adequate PEP, the rabies virus can travel within peripheral nerve axons at a rate of $12-24$ $\mathrm{mm} /$ day from the wound to central nervous system neurons, causing irrevocable encephalitis that results in inevitable fatality. ${ }^{27}$ Rabies PEP requires RIG administration as soon as feasible following exposure (contaminated injury or bite); however, sources and supply are often limited, particularly in resource-poor settings. ${ }^{15,16}$

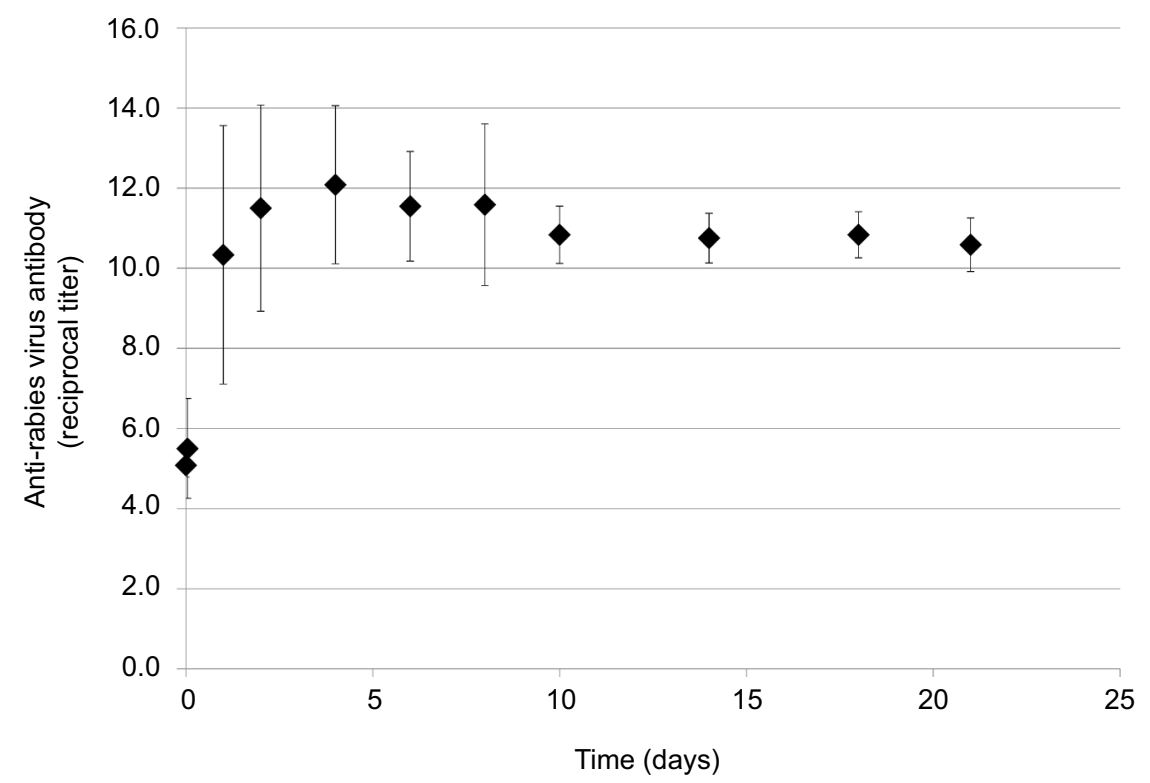

Figure 3 Reciprocal of anti-rabies virus antibody titer by RFFIT following a single IM dose of RIG-C (mean \pm SD).

Abbreviations: RFFIT, rapid fluorescent focus inhibition test; IM, intramuscular; RIG-C, rabies immune globulin purified by caprylate/chromatography; SD, standard deviation. 
Table 4 Treatment-emergent adverse event frequency by subject $(n=12)$

\begin{tabular}{|c|c|c|}
\hline System organ class preferred term & Within 24 hours, $n$ (\%) & Overall, n (\%) \\
\hline Number of subjects with any $A E$ & $4(33)$ & $6(50)$ \\
\hline Total number of $A E s$ (number of events) & 10 of $15 \mathrm{AEs}$ & $15 \mathrm{AEs}$ \\
\hline Gastrointestinal disorders & $\mathrm{I}(8)$ & I (8) \\
\hline Abdominal pain & $I(8)$ & $I(8)$ \\
\hline Diarrhea & $I(8)$ & I (8) \\
\hline Flatulence & $1(8)$ & $1(8)$ \\
\hline General disorders and administration site conditions & $4(33)$ & $5(42)$ \\
\hline Injection site pain & $3(25)$ & $4(33)$ \\
\hline Injection site nodule & $\mathrm{I}(8)$ & $\mathrm{I}(8)$ \\
\hline Injury, poisoning, and procedural complications & $0(0)$ & $\mathrm{I}(8)$ \\
\hline Procedural dizziness ${ }^{\mathrm{a}}$ & $0(0)$ & $I(8)$ \\
\hline Musculoskeletal and connective tissue disorders & $0(0)$ & $I(8)$ \\
\hline Pain in extremity & $0(0)$ & $\mathrm{I}(8)$ \\
\hline Nervous system disorders & $I(8)$ & $I(8)$ \\
\hline Headache & $I(8)$ & $\mathrm{I}(8)$ \\
\hline Respiratory, thoracic, and mediastinal disorders & $0(0)$ & $2(17)$ \\
\hline Nasal congestion & $0(0)$ & $1(8)$ \\
\hline Oropharyngeal pain & $0(0)$ & I (8) \\
\hline
\end{tabular}

Notes: andicates unrelated adverse events in I patient each. Time frame refers to within 24 hours of RIG-C administration.

Abbreviations: AE, adverse events; RIG-C, rabies immune globulin purified by caprylate/chromatography.

Grifols' original hRIG, first licensed in 1974, was the first hRIG product licensed in the US. In 1996, solvent/detergent HyperRAB S/D was introduced with a pH of 6.4-7.2 and an average potency of $150 \mathrm{IU} / \mathrm{mL}$. Recently, Grifols developed a new manufacturing process for RIG-C using caprylate/ chromatography purification, which is the same purification process for Gamunex-C, thereby further enhancing purity. Relative to $150 \mathrm{IU} / \mathrm{mL}$ of other hRIG products, this new RIG-C preparation has a higher rabies antibody potency of $300 \mathrm{IU} / \mathrm{mL}$, allowing for smaller injection volumes. However, since the RIG-C dose (20 IU/kg) is the same, this new formulation will not interfere with vaccine-induced immunity. Following a rabid animal bite, the full dose of hRIG must be infiltrated into and around the wound with any remaining volume injected IM. Given the $300 \mathrm{IU} / \mathrm{mL}$ concentration of RIG-C (twice that of other currently available hRIG products), half the volume is necessary to deliver the standard $20 \mathrm{IU} / \mathrm{kg}$ dose of $300 \mathrm{IU} / \mathrm{mL}$ RIG-C compared to $150 \mathrm{IU} / \mathrm{mL} \mathrm{hRIG}$ products. With the typical maximum IM injection volume being $5 \mathrm{~mL}$ for a single injection site,,${ }^{14}$ the higher RIG-C concentration minimizes the number of IM injections, and maximizes the portion of the dose that can be infiltrated locally into and around the wound. Importantly, rabies vaccine is also administered at a site distant from the hRIG injection site on days $0,3,7$, and 14 (5th dose on day 28 if required) after rabid animal bite to raise the host protective antibodies high enough for protection against rabies infection. ${ }^{5}$
RIG serves as an essential part of PEP. RIG neutralizes rabies virus and impedes virus propagation when infiltrated around the wound. While adequate antibody titers are not achieved by RIG alone, RIG provides an interim level of passive immunity before vaccine-induced antibodies can be formed. This bridge diminishes the likelihood of prophylaxis failure substantially. About 7-10 days after the first vaccine dose, active immunization produces virus neutralizing antibodies concentrations that peak between day 14 and day 28 (after administration of 4 vaccine doses). ${ }^{5}$ Guidelines for rabies immunization practices, including passive immunization, are available through the Centers for Disease Control and Prevention ACIP and the WHO.

For the purposes of defining "adequate immunization" with rabies vaccine, the ACIP recommends complete neutralization of rabies virus at a serum dilution of 1:5 as minimum evidence of circulating rabies virus neutralizing antibodies. ${ }^{4,5,28}$ This infers a $100 \%$ endpoint titer on RFFIT, which is appropriate when vaccine-induced native humoral response is being assessed in the setting of potentially lethal rabies virus exposure. Generally in virology, considerable over-capacity of neutralizing antibody is required to achieve protection at the time of virus challenge. ${ }^{29}$ This is the aim of vaccination. The current study measured the passive transfer of rabies neutralizing antibodies using a $50 \%$ endpoint titer, which was chosen intentionally as a lower threshold than the vaccine-induced antibody concentration since the aim was not to interfere with the crucial vaccine response. Thus, 
a reciprocal titer of 5 within the confines of this study $(50 \%$ neutralization endpoint) is not the same as the ACIP vaccine immunization threshold that utilizes a $100 \%$ neutralization endpoint at a 1:5 dilution.

RIG has the critical function of providing passive transfer of rabies neutralizing antibody sufficient to allow time for a naïve immune system to respond robustly to vaccination. However, there is delicate equipoise, because RIG passive antibody transfer must be sufficiently low to avoid inhibiting vaccine response. The WHO Expert Committee on Rabies indicated that the seroprotective level of serum rabies virus neutralizing antibodies in persons with exposure to rabies is $\geq 0.5 \mathrm{IU} / \mathrm{mL} .^{3}$ As anticipated in this study, anti-rabies virus antibody concentrations remained below $0.5 \mathrm{IU} / \mathrm{mL}$ because rabies vaccine was not administered. This is consistent with the aim of providing interim passive antibody levels sufficient to support, but not impair, intrinsic immune response to vaccine. Excessive amounts of passive antibody administration can interfere with the production of a host's own antibody response. Interference phenomena have been observed in several studies, ${ }^{30-33}$ including evaluation of hRIG given at a higher than recommended dosage (eg, $40 \mathrm{IU} / \mathrm{kg}$ hRIG in combination with various vaccine regimens). In this study, RIG-C produced a substantial increase in anti-rabies virus antibody concentrations during the time period in which peak values were achieved. Elevated antibody levels and the corresponding reciprocal titers persisted through day 21 . Eleva- tion in rabies antibody level was prompt and demonstrable within 24 hours of administration (mean $0.113 \mathrm{IU} / \mathrm{mL}$ and mean titer 10.3 on day 1 ).

The reciprocal titer results from this study are comparable to an earlier open-label, single-center study of Grifols RIGS/D (Bayer data on file 1996, Report MRR 1321) in 8 subjects given a $20 \mathrm{IU} / \mathrm{kg}$ dose IM via two injections (Figure 4). In this previous study of RIG-S/D, peak reciprocal titers of 11 were observed by approximately 48 hours postdose, and individual titers ranged from 6 to 14 during the interval from dosing to day 21 . In the current study of RIG-C, a mean reciprocal titer of 11.5 was realized by approximately 48 hours postdose, and peak mean titers occurred at day 4 (mean 12.1) with mean titers ranging from 10.3 to 12.1 during day 1 -day 21 .

Additionally, these results were comparable to data from the published study ${ }^{34}$ by Pasteur Merieux Connaught comparing heat-treated $(\mathrm{H}-\mathrm{T}) \mathrm{hRIG}\left(60^{\circ} \mathrm{C}\right)$ and $\mathrm{hRIG}$ without pasteurization in 16 subjects per group. Lang et al reported results solely in $\mathrm{IU} / \mathrm{mL}$. For those subjects randomized to receive $\mathrm{hRIG}$ alone (without vaccination), the maximum geometric mean value was $0.084 \mathrm{IU} / \mathrm{mL}$ (95\% confidence interval (CI) $0.046-0.155 \mathrm{IU} / \mathrm{mL}$ ) for $\mathrm{H}-\mathrm{T} \mathrm{hRIG}$ and 0.074 $\mathrm{IU} / \mathrm{mL}(95 \%$ CI $0.042-0.152 \mathrm{IU} / \mathrm{mL})$ in the hRIG without pasteurization. ${ }^{34}$ The geometric mean values for $\mathrm{RIG}-\mathrm{C}$ in the current study compare favorably with these data, confirming the effectiveness for passive transfer of rabies neutralizing antibodies. The data for the original Merieux hRIG (when

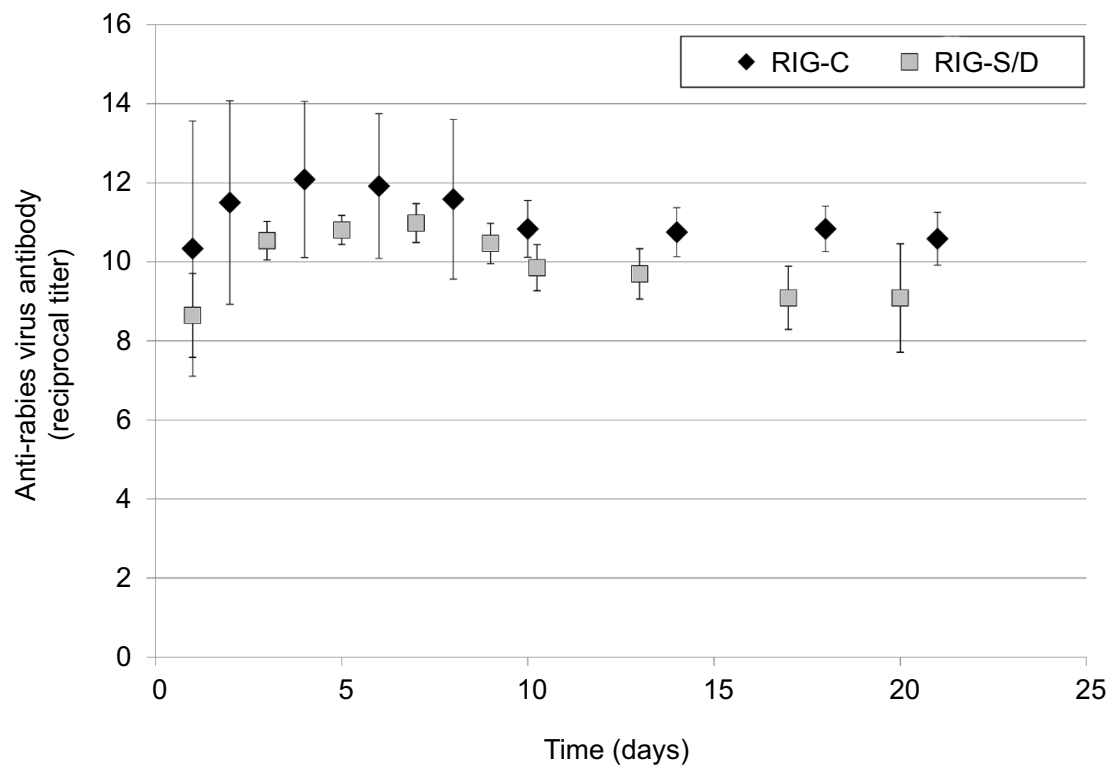

Figure 4 Reciprocal of anti-rabies virus antibody titer following a single IM dose of RIG-C or RIG-S/D product (mean \pm SD).

Notes: This graph depicts the mean (SD) RFFIT results for both RIG-C (black diamond) and RIG-S/D (gray square) products. Data for RIG-S/D were derived from the Bayer data on file 1996, Report MRR I32I of 8 healthy adult subjects who received a 20 IU/kg IM dose of RIG-S/D in two injections.

Abbreviations: IM, intramuscular; RIG-C, rabies immune globulin purified by caprylate/chromatography; RIG-S/D, rabies immune globulin purified by solvent/detergent; SD, standard deviation; RFFIT, rapid fluorescent focus inhibition test. 
given alone to 16 subjects) produced a geometric mean value of $0.10 \mathrm{IU} / \mathrm{mL}$ on day 3 , which again was comparable to the geometric mean achieved with RIG-C. ${ }^{33}$

\section{Limitation}

This study included a relatively small sample size of healthy volunteers albeit sufficient to demonstrate detectable neutralizing rabies antibody.

\section{Conclusion}

This study demonstrated that caprylate/chromatography purified hRIG (RIG-C) produced a rapid increase in rabies neutralizing antibodies within 24 hours, peaked on day 4 , and maintained through day 21 . These results support the conclusion that RIG-C administration provides reproducible passive transfer of neutralizing antibodies commensurate with Grifols HyperRAB S/D product. The single $20 \mathrm{IU} /$ $\mathrm{kg}$ IM dose of RIG-C was safe and well tolerated. RIG-C should provide adequate passive adjunctive treatment when combined with vaccination in accordance with guidelines for rabies exposure. This new RIG-C formulation has twice the potency $(300 \mathrm{IU} / \mathrm{mL})$ of currently available RIG options $(150 \mathrm{IU} / \mathrm{mL})$, offering a greater concentration of anti-rabies virus antibodies within each $\mathrm{mL}$ of volume, and for patients, the potential for fewer injections by significantly reducing the injection volume of each dose.

\section{Data sharing statement}

The datasets generated and/or analyzed during the current study are not publicly available due to the fact that the US Food and Drug Administration does not require posting of Phase I data.

\section{Acknowledgments}

The authors would like to thank Tam M Nguyen-Cao, PhD, of Grifols for providing medical writing assistance under the direction of the authors. The authors appreciate the dedication of site staff and the commitment of enrolled subjects. This study was funded in full by Grifols, a manufacturer of RIG-C and RIG-S/D.

\section{Author contributions}

$\mathrm{KH}$ contributed to the conception and design, data acquisition, analysis and interpretation of the data. MCC contributed to the analysis and interpretation of the RFFIT data. EM was the medical monitor of this study from July 1, 2014 to study completion, contributed to the interpretation of all data, and drafted the first version of the manuscript. EC contributed to the study design and data acquisition, and managed the study conduct. PV contributed to analysis and interpretation of the RFFIT data. All authors made substantive contributions to revising the manuscript critically for important intellectual content, gave final approval to the version to be published, had full access to the data in the study, and took responsibility for the integrity of the data and the accuracy of the data analysis.

\section{Disclosure}

All the authors are employees of Grifols and report personal fees from Grifols during the conduct of the study. The authors report no other conflicts of interest in this work.

\section{References}

1. Jackson AC. Rabies. In: Tselis AC, Booss J, editors. Handbook of Clinical Neurology. Amsterdam: Elsevier B.V.; 2017;123:601-618.

2. Pasteur ML. Méthode pour prévenir la rage après morsure. [Method for preventing rabies after bite]. Comptes Rendus de L'Académie des Sciences. [Accounts of the Academy of Science]. 1885;101:765-772. French.

3. World Health Organization. WHO Expert Consultation on Rabies: Second Report. WHO Technical Report Series 982. Geneva: World Health Organization; 2013:1-139.

4. Manning SE, Rupprecht CE, Fishbein D, et al. Advisory Committee on Immunization Practices Centers for Disease Control and Prevention (CDC). Human rabies prevention — United States, 2008: recommendations of the Advisory Committee on Immunization Practices. MMWR Recomm Rep. 2008;57(RR-3):1-28.

5. Rupprecht CE, Briggs D, Brown CM, et al. Advisory Committee on Immunization Practices Centers for Disease Control and Prevention (CDC). Use of a reduced (4-dose) vaccine schedule for postexposure prophylaxis to prevent human rabies: recommendations of the advisory committee on immunization practices. MMWR Recomm Rep. 2010;59(RR-2):1-9.

6. Anderson A, Shwiff SA. The cost of canine rabies on four continents. Transbound Emerg Dis. 2015;62(4):446-452.

7. World Health Organization [webpage on the Internet]. Other rabies biological products. In: Rabies Information Resources. 2018 [cited March 23, 2018]. Available from: http://www.who.int/rabies/resources/ other_rabies_biolog_product/en/.Accessed March 23, 2018.

8. HyperRAB $® \mathrm{~S} / \mathrm{D}$ (rabies immune globulin [human]) [package insert]. Research Triangle Park, NC: Grifols Therapeutics Inc.; 2012.

9. Imogam ${ }^{\circledR}$ Rabies - HT (rabies immune globulin [human]) USP, Heat Treated [package insert]. Marcy L'Etoile: Sanofi Pasteur; 2014.

10. KEDRAB (rabies immune globulin [human]) [package insert]. Fort Lee, NJ: Kedrion Biopharma Inc; 2017.

11. HYPERRAB (rabies immune globulin [human]) solution for infiltration and intramuscular injection [package insert]. Research Triangle Park, NC: Grifols Therapeutics LLC; 2018.

12. GAMUNEX ${ }^{\circledR}-\mathrm{C}$ (immune globulin injection [human], 10\% caprylate/ chromatography purified) [package insert]. Research Triangle Park, NC: Grifols Therapeutics Inc.; 2017.

13. SAGE Working Group on Rabies Vaccines and Immunoglobulins and the World Health Organization (WHO) Secretariat. Background paper: proposed revision of the policy on rabies vaccines and rabies immunoglobulins. 2017 [cited January 20, 2018]. Available from: http:// www.who.int/immunization/sage/meetings/2017/october/1_Background_paper_WG_RABIES_final.pdf. Accessed January 29, 2018. 
14. Hopkins U, Arias CY. Large-volume IM injections: a review of best practices. Oncol Nurse Advisor. 2013;4(1):32-37.

15. Both L, Banyard AC, van Dolleweerd C, Horton D, Ma JK, Fooks AR. Passive immunity in the prevention of rabies. Lancet Infect Dis. 2012;12(5):397-407.

16. Crowcroft NS, Thampi N. The prevention and management of rabies. BMJ. 2015;350:g7827.

17. Moore SM, Hanlon CA. Rabies-specific antibodies: measuring surrogates of protection against a fatal disease. PLoS Negl Trop Dis. 2010;4(3):e595.

18. Smith JS, Yager PA, Baer GM. A rapid reproducible test for determining rabies neutralizing antibody. Bull World Health Organ. 1973;48(5):535-541.

19. Cliquet F, Aubert M, Sagné L. Development of a fluorescent antibody virus neutralisation test (FAVN test) for the quantitation of rabiesneutralising antibody. J Immunol Methods. 1998;212(1):79-87.

20. Cliquet F, Barrat J. Rabies. In: OIE Biological Standards Commission, editor. Manual of Diagnostic Tests and Vaccines for Terrestrial Animals (Mammals, Birds and Bees). Vol 1. 5th ed. Paris: OIE Biological Standards; 2004:329-346.

21. Fitzgerald EA, Cabasso VJ, Smith JS, Rastogi SC. A collaborative study on the testing of rabies immune globulin (human) by the mouse neutralization test (MNT) and the rapid fluorescent focus inhibition test (RFFIT). J Biol Stand. 1979;7(1):67-72.

22. Fitzgerald EA, Rastogi SC. A collaborative study to establish an International Standard Rabies immunoglobulin of human origin. J Biol Stand. 1985;13(4):327-333.

23. Habel K. Habel test for potency. In: Meslin FX, Kaplan MM, Koprowski $\mathrm{H}$, editors. Laboratory Techniques in Rabies. 4th ed. Geneva: World Health Organization; 1996:369-373.

24. International Conference on Harmonisation (ICH) Expert Working Group (Quality). ICH Harmonised Tripartite Guideline. Validation of Analytical Procedures: Text and Methodology Q2(R1). CPMP/ICH/381/95. 1995 [cited December 12, 2017]. Available from: https://www.ich.org/fileadmin/Public_Web_Site/ICH_Products/Guidelines/Quality/Q2_R1/Step4/ Q2_R1_Guideline.pdf. Accessed December 12, 2017.
25. Guidance for Industry Bioanalytical Method Validation. Center for Drug Evaluation and Research (CDER) and Center for Veterinary Medicine (CVM). 2001 [cited December 12, 2017]. Available from: https:// www.fda.gov/downloads/Drugs/Guidance/ucm070107.pdf. Accessed December 12, 2017

26. Kostense S, Moore S, Companjen A, et al. Validation of the rapid fluorescent focus inhibition test for rabies virus-neutralizing antibodies in clinical samples. Antimicrob Agents Chemother. 2012;56(7):3524-3530.

27. Lycke E, Tsiang H. Rabies virus infection of cultured rat sensory neurons. J Virol. 1987;61(9):2733-2741.

28. Centers for Disease Control and Prevention [webpage on the Internet]. Rabies serology. 2016 [updated April 15, 2016; cited December 8, 2017]. Available from: https://www.cdc.gov/rabies/specific_groups/doctors/ serology.html. Accessed December 8, 2017

29. Burton DR. Antibodies, viruses and vaccines. Nat Rev Immunol. 2002;2(9):706-713.

30. Vodopija I, Sureau P, Smerdel S, et al. Interaction of rabies vaccine with human rabies immunoglobulin and reliability of a 2-1-1 schedule application for postexposure treatment. Vaccine. 1988;6(3): 283-286.

31. Lang J, Simanjuntak GH, Soerjosembodo S, Koesharyono C. Suppressant effect of human or equine rabies immunoglobulins on the immunogenicity of post-exposure rabies vaccination under the 2-1-1 regimen: a field trial in Indonesia. MAS054 Clinical Investigator Group. Bull World Health Organ. 1998;76(5):491-495.

32. Warrell MJ, Warrell DA, Suntharasamai P, et al. An economical regimen of human diploid cell strain anti-rabies vaccine for post-exposure prophylaxis. Lancet. 1983;2(8345):301-304.

33. Helmick CG, Johnstone C, Sumner J, Winkler WG, Fager S. A clinical study of Merieux human rabies immune globulin. J Biol Stand. 1982;10(4):357-367.

34. Lang J, Gravenstein S, Briggs D, et al. Evaluation of the safety and immunogenicity of a new, heat-treated human rabies immune globulin using a sham, post-exposure prophylaxis of rabies. Biologicals. 1998;26(1):7-15.
Clinical Pharmacology: Advances and Applications

\section{Publish your work in this journal}

Clinical Pharmacology: Advances and Applications is an international, peer-reviewed, open access journal publishing original research, reports, reviews and commentaries on all areas of drug experience in humans. The manuscript management system is completely online and includes a very quick and fair peer-review system, which is all easy to use.

\section{Dovepress}

Visit http://www.dovepress.com/testimonials.php to read real quotes from published authors. 